\title{
浅析建构主义理论与中级汉语口语教学
}

\section{A BRIEF ANALYSIS ON CONSTRUCTIVISM THEORIES \\ AND INTERMEDIATE CHINESE CONVERSATION TEACHING}

\author{
Temmy \\ Chinese Department, Faculty of Humanities, BINUS University \\ Jln. Kemanggisan Ilir III No.45, Kemanggisan - Palmerah, Jakarta Barat 11480 \\ temmy@binus.edu
}

\section{内容摘要}

建构主义认为学习是在一定的情境中即社会文化背景下, 借助其他人的帮助即通过人际间的协作活 动而实现的意义构建过程。这一突破传统的理论对于中级汉语口语教学具有很大的启示。本文从建构主 义理论出发, 联系学习者话语产生的心理机制以及中级汉语口语教学的特点, 探讨在中级汉语口语教学 中运用建构主义理论的可行性和适用性，以期能获得启示，更好地推动中级汉语口语课的教学。

关键词：建构主义理论，口语教学，可行性，适用性

\begin{abstract}
Constructivism theories believe that learning process should be conducted under a specific condition, which is social and cultural background of the target language. Learner's language ability is built through communication and activities that helps to shape meaningful construction. This theory has a very high impact on teaching conversation. This article discusses the Constructivism theory, its relation on learner's word production, psychological mechanism and teaching intermediate conversation's characteristics, as well as the feasibility and applicability of Constructivism theory in the process on teaching intermediate conversation.
\end{abstract}

Keywords: Constructivism Theories, Teaching Conversation, Feasibility, Applicability 


\section{前言}

在对外汉语教学的发展过程中, 国外的各种语言学、心理学、教育学及教育心理学理论发 挥了十分重要的借鉴指导作用。近年来, 西方的建构主义理论引起了对外汉语教学界越来越多 的关注。但与英语教学对建构主义的研究相比, 同样身为二语教学的对外汉语教学对于建构主 义的研究运用还处于起步阶段。在中国知网搜索到的 320 篇建构主义与教学的论文中, 仅有 5 篇是关于建构主义与对外汉语教学的, 且其大多是从宏观角度阐述建构主义对汉语教学的启示。 应该说, 除了宏观的理论阐述之外, 若能将建构主义理论与具体的汉语听、说、读、写等课型 结合起来, 对对外汉语教学的发展是大有裨益的。

鉴于上述情况, 本文尝试在前辈研究的基础上, 探讨 “建构主义理论对中级汉语口语教学 的启示”。本文将通过分析阐述建构主义的理论核质, 联系汉语学习者口语产生的认知心理过程, 从建构主义的视角出发审视汉语口语教学, 以期获得更多教学上的启示, 以促进中级对外汉语 口语教学的发展。

\section{内容}

\section{建构主义基本原理}

一、建构主义的主要观点

建构主义认为知识不是通过教师传授得到的, 而是学习者在一定的情境中即社会文化 背景下, 借助其他人 (包括教师和学习伙伴) 的帮助即通过人际间的协作活动而实现的意 义构建过程。

二、建构主义的主要内容

(一)、关于知识的观点

建构主义认为知识不是对现实世界的纯粹的客观的精确的反映, 它只是人们 对世界的一种解释或者是对问题解决的假设。因此它必须依赖于具体的认知个体, 具有个体性。对于看似普遍的课本知识, 每个个体学习者都会以自己独特的经验 背景和特殊情景为基础对之进行理解, 这样他们的理解必然也不尽相同。

(二)、关于学习者的观点

建构主义强调学习者并不是空着脑袋走进课堂的, 他们在日常生活和以往各 种形式的学习中, 已经形成了有关的知识经验, 对任何事物都有自己的看法。

(三)、关于学习活动的观点

建构主义认为学习是一个积极主动的建构过程, 学习者根据先前认知结构主动 地和有选择地知觉外在信息, 建构其意义, 反映出来的一种双向性的建构过程, 而且这个过程必须经过 “同化” 和 “顺应” 两个过程。同化即整合, 即把新的信 息整合进原有的认知结构中去, 其结果是认知结构 “量” 的扩展。顺应即重组, 即新的信息无法整合进原有的认知结构中, 这时, 学习者就要促使它在结构上发 
生变化, 调整为新的认知结构, 其结果是认知结构 “质” 的变化。这样才能完成 一个 “平衡——不平衡——平衡” 的认知发展过程。

(四)、关于学习环境

建构主义十分重视学习环境的作用, 并指出学习环境有以下 4 个要素:

1. 情境: 是指学习者发生学习活动的社会文化背景, 它必须有利于学习者对所学 内容的意义构建。情境的创设是教学设计最重要的内容之一。

2. 协作: 是指学习者在学习过程中与教师和同学的相互作用, 贯穿于学习过程的 始终, 推进每个学习者的学习进程。

3. 会话: 是协作过程中不可缺少的环节, 是达到意义构建的重要手段之一。

4. 意义构建: 是整个学习过程的最终目标。在学习过程中帮助学生构建意义, 就 是帮助学生对当前学习内容所反映的事物的性质、规律以及该事物与其他事物 之间的内在联系达到较深刻的理解。

(五)、关于教学模式: 有了上述一系列的思想作基础, 建构主义的教学模式可以概括为: 以学生为中心, 在整个教学过程中教师起组织者、指导者、帮助者和促进者的作用, 利用情境、协作、会话等要素充分发挥学生主动性、积极性和首创精神, 最终达到 使学生有效实现对当前所学知识的意义构建的目的。

\section{建构主义理论在中级对外汉语口语教学中的可行性和适用性}

对外汉语口语教学课堂是学习者系统学习和训练汉语口语最主要和最重要的途径。在教学 过程中, 经常出现学生参与性不强、开口率不高、机械的模仿替换练习过多而模拟情景交际训 练不足的现象, 使得学生往往只在当时学到了语言的形式, 而没有掌握语言的功能, 更没有将 其 “内化” 到他原有的知识结构中去, 导致学生无法适应外界真实交际情况, 对口语学习失去 动力和热情。尤其是到了中级阶段, 学习者虽然已经掌握了一定的汉语知识, 但也相对容易进 入汉语学习的 “瓶颈期”, 在实际运用汉语时不能很好地启动自身的语料库存, 活化已掌握的语 言规则, 巩固已有的话语结构, 习得新的表述方式, 面对这种种的问题, 能否从建构主义的理 论中得到一些启示呢? 建构主义理论是否符合学习者话语产生的认知过程, 是否符合中级汉语 口语教学的特点和需求呢?

\section{一、建构主义理论符合学习者话语产生的认知心理过程}

\section{(一)、话语的产生过程}

相关研究表明, 话语的产生在内部实质上是一种语言产生的心理过程。首先, 输出话语的先决条件是语言的输入。外界的言语刺激信息通过视觉、听觉进行感 觉登记, 再由神经元传导给短时记忆, 在这儿经过复现和再现, 有关的语言信息 和语言结构就落到了长时记忆, 永久储存。这就是输入。其次, 当外界又有言语 信息刺激感官时, 被神经元传导到大脑言语中枢的长时记忆库, 大脑机制就会寻 找与外界刺激信息相似或相近的言语（词语和句子）模式, 进行匹配, 匹配不上 的, 就作为新知而输入, 匹配上的, 就将他们提取到类似短时记忆 (心理学家称 为工作记忆）框中, 根据接收者的经验和语感去切分音节和意群, 领会话语的意 义。此即为语言的理解。而如要把内心的某个思想表达出来, 则必须经过话语计 划、话语构建、话语计划的执行三个阶段。即根据头脑中的意图, 从长时记忆中 选择合适的词语, 提取到工作记忆, 按照语法规则进行装配、组合, 再转换成语 
音 (或文字) 串, 形成话语（口语或书面语）。因此, 可以说话语的产生过程, 实 际上包含着接受——辨识——理解——储存一一反映一一提取一一整理——编码 一发送一一传播等一系列的心理活动的组合。

\section{（二）、从建构主义视角看话语的产生过程}

仔细分析上述过程, 不难发现, 外语学习者口语的学习过程实质上也是一种 双向构建的过程, 是学习者积极主动地实现意义构建的过程。若把这一过程放在 汉语口语教学的课堂上, 就可以发现学习者汉语口语的学习经历着以下这样一个 意义构建的过程。

首先, 学习者先是在课堂上从教师那获得一定的汉语知识的输入, 以记忆储 存一定的目的语词语和句子等语言材料, 在头脑中逐步建立起汉语语言结构和语 义的网络体系。但这种 “获取” 并不是被动地单方面接受。正如建构主义所强调 的, 学生并不是空着脑袋走进教室的, 他们已有的生活经验和文化背景或是已经 具备的汉语知识都会影响他们对所学习的新知识的接受和理解。在学习汉语时, 学习者并不是把全新的信息从外界搬到头脑中, 而是一方面以已有的信息为基础, 通过与外界的相互作用来建构新的理解。另一方面, 在对新的信息的意义建构的 同时又对原有信息进行改造和重组。在接受一一辨识——理解一一储存这一系列 的过程中, 学习者会不可避免地经历 “同化” 和 “顺应” 这两个过程。当他们学 习新的生词或是句型时, 若能利用已知的认知结构把新信息整合到其中, 达到了 平衡, 即完成了 “同化”。而另一方面, 当学习者不能利用原有的认知结构来接受 和解释新的信息时, 他们的认知结构会由于新信息的影响而发生改变以达到新的 平衡。当然, 这种建构的过程绝不是轻而易举就可以顺利完成的。因为新接收的 有关汉语知识的信息与学习者的母语及其文化 (特别是母语与汉语差异较大的学 习者来说）是两个完全不同的系统, 很多时候, 汉语的 “难” 并不表现在汉语本 身, 而表现在学习者过去具有的语言知识、语言获得知识和文化背景在他们学习 汉语时很难发挥积极的作用。再加上他们来华学习汉语所获得的目的语知识在他 们已有的认知结构中又只占极小部分, 而且常常不成系统。所以学习者在学习过 程中, “同化” 所占的比例有限, 更多的是 “顺应”。再加上学习者的汉语水平有 限, 在将新信息与已有的经验成分分析、对比、融合、替代的过程中, 不可避免 地会发生 “不正确” 的信息建构过程, 增加学习者学习的难度。这时, 就需要汉 语教师从学生出发, 运用各种教法, 调动各种外部和内部的积极因素, 促进学习 者新旧知相互作用, 或是有意识地创设情境, 引发认知冲突, 使学生通过 “顺应” 的过程, 调整原有知识结构, 以顺利接纳新知识。

其次, 在教师展示了口语课的知识点之后, 学习者必须通过各种形式的操练 来掌握如何运用他们刚学到的新知识。课堂上学习到的生词和句式等都只是一种 陈述性的知识, 必须要通过成千上万个小时的练习之后, 知识才能达到程序化和 自动化。在这个过程中, 模仿、替换、变换、扩展等机械练习当然是必不可少的, 但这些操练往往只关注了语言的形式, 而忽视了语言的功能。单凭这些并不能帮 助学习者适应真实交际情境, 将所学的语言结构内化。而这时就需要汉语教师营 造出有意义的会话的学习环境, 形成良好的师生、生生互动, 这样不仅有利于学 生内化新知、提高课堂参与度, 也为他们在真实交际环境中自如运用打下基础。 


\section{(三)、结论}

从以上对话语产生机制以及学习者课堂语言获得的阐述中，可以得出以下结 论: 建构主义理论是符合汉语学习者话语产生的认知心理规律的: 在口语课堂上, 学习者是知识意义的主动构建者, 他们一方面要学会利用语言体系中的材料建构 话语，表达思想，使抽象的语言规则内化成为一种深层的语言格局和惯性；另一 方面又要从话语中学习新的语言材料, 建构个体掌握的语言体系。从根本上看, 学习者对汉语的掌握的过程就是他们对汉语这种语言体系的个体建构的过程。因 此，在汉语口语教学中运用建构主义理论是可行的。

二、建构主义理论适合中级汉语口语教学的特点和需要

建构主义强调学习者的主动性, 同时也肯定教师的指导促进作用, 主张教师从学生实 际情况出发, 利用情景、协作和会话等要素设计出较好的学习环境, 帮助学生通过探索发 现、协作交际实现意义构建。这些理念均符合中级汉语口语教学的要求, 能有效指导教师 组织课堂教学的各个环节。具体表现在:

1、以建构主义为指导, 创设以学生为中心的口语课堂

建构主义强调 “教师指导指导下的, 以学生为中心的学习”, 教师的一切教学设计 均是围绕 “学”而展开, 学生的活动贯穿于教学过程的始终。这一点突出了口语课“说” 的特点。尤其到了中级阶段, 学生已掌握了一定的语言知识和技能, 教师所要做的是 调动学生的主动性, 使他们通过 “多说” 有机会实现语言结构的内化和形成解决实际 问题的语言能力。

2、以建构主义为指导，创设情境性的口语课堂环境

建构主义认为学习环境的作用很重要, 希望学习环境接近真实、从而使学习能适 应不同的问题情境、在实际生活中能有更广泛的应用。这一点与中级汉语口语课的教 学内容和特点相符合。到了中级阶段, 学生已掌握了必要的语言知识和技能, 就应该 开始学习口语的特殊成分和组织规则, 而这些成分和规则超出了单纯的语言成分和语 法的范围, 而是涉及语境、场景乃至社会文化等各种因素, 属于语用的范围。中级汉 语口语课的重点就是要教授这些在别的课中学不到的口语语用知识和技能, 而教师是 否能利用情境、协作和会话等要素创造出良好的学习环境, 对学习者能否真正掌握这 些语用知识和技能起着至关重要的作用。

3、以建构主义为指导, 促进口语课堂的互动

建构主义认为学生作为意义的主动构建者, 需要通过探索和协作学习来构建知识, 这一点对于中级汉语课的课堂互动有很好的启示作用。中级阶段学生的说话的欲望和 要求很强烈, 他们更喜欢的是自我尝试将已掌握的语言知识推广运用到其他情境中去, 而非初级阶段的跟随老师机械重复和被动模仿。教师可以有意识的为学生创造 “发现 探索” 的环境, 而师生、生生之间的互动就是一个很好的机会。通过与教师和学习伙 伴之间的相互合作、对话, 不仅有利用学习者知识的重新建构, 还可以超越他们自己 的认识, 看到那些与自己不同的理解, 看到事物的另外侧面, 丰富自己的知识, 利于 学习的广泛迁移, 促进知识的记忆。 


\section{建构主义理论对中级汉语口语教学的启示}

综上所述，建构主义理论对汉语教师如何充分利用情境、会话、协作等要素，设计出真正 “以学生为中心” 的口语课堂教学, 提高学生上口语课的积极性和参与性, 切实提高他们的语 言交际能力具有重要的启示。

一、以学生为中心, 激发学习兴趣。

这首先是指教师要注意选择话题。口语课上常常会发生讨论开展不起来的情况, 而这 其中就隐含了如下几种原因: 要么学生的汉语水平不够、或是对这方面不了解、或是文化 背景有差异, 或是对这个话题根本没兴趣。所有这些都违反了会话的合作原则。[所以, 教 师在教学设计时要以学生为本, 充分考虑到学生的背景和汉语水平, 选择他们有话想说而 同时又有话可说的话题。

其次, 以学生为中心, 还要求教师在教学过程中, 要用引思设疑、商讨启发的方式给 与学生独立思索的空间、从而引导他们发现探索新知, 而不是一味地 “满堂灌”。学生作为 意义的主动构建者, 如通过自己发现例子之间的关系而学习使用规则, 比教师给予他们一 系列的 “灌输” 知识更能从学习过程中发现新的知识。因此、在课堂教学中要有意识地为 学生创造 “发现” 的环境。

二、利用各种信息资源创设真实的情境

中级汉语口语课的性质是语用的教学, 表达和交际训练的比重有很大的增加。而中级 阶段的学生虽然已掌握了一定的语言规则, 但其汉语知识常常处于静态之中, 在需要时无 法灵活地提取。这就要求教师为学生提供一个模拟的真实情境, 使学生能有机会在一个特 定的情境组合中运用所学的相关语言知识, 使语言在运用中活化起来。此外, 在口语教学 中, 营造情境并以情境为依托, 可以使新词组或句式的掌握和记忆花比较少的时间, 并提 供新词语与已学过的词语以更广泛的搭配功能上的条件。徐子亮教授指出, 在情境的设计 时应注意以下几个方面:（1）情境的设计要具有开拓性和延续性（2）情境的设计要处理好 会话双方的输入性与输出性的技能训练的比重, 使交际双方都有适当的输入或输出技能的 训练机会（3）情境的设计应当有针对性（4）情境设计应当明确化、具体化。

教师应根据以上这些原则, 充分利用各种信息资源如: 录音、图片、电影电视中的片 段等等营造生动的、形象的语境和交际环境, 帮助学生理解和练习, 达到更好的学习效果。

三、强调协作学习的重要作用, 鼓励学生进行互动与合作

口语的课堂教学中, 教师的讲解代替不了学习者的练习, 同时口语的教学也要求语句 的重现和复现。这就使得学生之间的互动和协作显得十分重要。首先, 互动给了学生充分 的时间来练习新学的语言知识, 而与此同时、也增加了新知识的重现率和复现率, 促进学 生的记忆。其次, 每个学生的个体思想呈开放式, 对某一问题的观点会千差万别, 在学生 的互动过程中, 学生可以接受来自多方面的信息。收集的信息越多越可靠, 所收获的知识 也就越真实有用。互动有助于学生重新构建知识, 检验已有的信息, 还可以超越自己的认 识, 看到那些与自己不同的理解, 丰富自己的知识, 有利于学习的广泛迁移。除此之外, 学生间的互动与合作还可以减轻一些较内向学生的焦虑感, 提高课堂参与度。 


\section{小结}

综上所述, 建构主义这一全新的理论符合汉语学习者口语产生的心理机制, 也顺应 中级口语课的教学需要。它对于汉语教师如何创设出一个 “以学生为中心”的口语课堂 教学环境、最大程度地调动学生地积极性、使学生的语言运用能力在精心设计的教学环 节中逐步提高有着不可忽视的启示作用。汉语教师若能领会建构主义理论的精髓, 并创 造性地将其运用到中级汉语课的实践教学活动中，不失为一种积极而有意义的尝试。

\section{参考文献}

[1] 陈威《建构主义学习理论综述》学术交流 2007 年第 3 期

［2］陈威《建构主义学习理论综述》学术交流 2007 年第 3 期第 176 页第 8 行 (1)

[3] 刘志雅 黄建榕《论建构主义的学习理论》现代教育论从 2004 年第 3 期第 6 页第 1 行 (2)

[4] 陈威《建构主义学习理论综述》学术交流 2007 年第 3 期第 176 页第 27 行 (2)

[5] 何克抗 《建构主义的教学模式、教学方法与教学设计》北京师范大学学报 (社会科学版) 1997 年第 5 期第 75 页第 17 行一 20 行

[6] 徐子亮 吴仁甫《实用对外汉语教学法》北京大学出版社 2005 年 7 月第 1 版第 130 页第 4 -9 行 (3)

[7] 李晓琪 主编《对外汉语口语教学研究》商务印书馆出版 2006 年 7 月第 1 版第 349 页第 13 -15 行

[8] 李晓琪 主编《对外汉语口语教学研究》商务印书馆出版 2006 年 7 月第 1 版第 29018 行 (4)

[9］李晓琪 主编《对外汉语口语教学研究》商务印书馆出版 2006 年 7 月第 1 版第 104 页 第 $15-18$ 行 (4)

[10］李晓琪 主编《对外汉语口语教学研究》商务印书馆出版 2006 年 7 月第 1 版第 89-90（5）

[11］徐子亮 吴仁甫《实用对外汉语教学法》北京大学出版社 2005 年 7 月第 1 版第 137（5）

[12］李晓琪 主编《对外汉语口语教学研究》商务印书馆出版 2006 年 7 月第 1 版第 294 页倒数 第 7 行 (6) 